\title{
Determination of caftaric acid in tincture and rose water obtained from Rosae damascenae flores
}

\author{
Antoanela POPESCU ${ }^{\mathrm{a}}$, Nicoleta MATEI ${ }^{\mathrm{b}, *}$, Florentina RONCEA ${ }^{\mathrm{a}}$, \\ Horatiu MIRESAN $^{\mathrm{a}}$ and Georgeta PAVALACHE ${ }^{\mathrm{a}}$ \\ ${ }^{a}$ Faculty of Pharmacy, Ovidius University of Constanta, Constanta, Romania \\ ${ }^{b}$ Faculty of Applied Sciences and Engineering, Ovidius University of Constanta, Constanta, Romania
}

\begin{abstract}
Polyphenolic compounds were determined from a pharmaceutical (tincture) and a cosmetic preparation (rose water), both obtained from the Rosae damascenae flores. Separation of the phenolic compounds was done by a HPLC method, using a Zorbax XDB or equivalent column C18, $250 \mathrm{~mm}$ x 4,6 mm; 5 $\mu \mathrm{m}$. A gradient elution was performed with phosphoric acid and acetonitrile eluted under gradient conditions. The flow rate was $1.5 \mathrm{~mL} / \mathrm{min}$ and the injection volume was $20 \mu \mathrm{L}$. HPLC method for determination of caftaric acid presented in this paper, has been validated. The results were statistically analyzed with SPSS 10 software.
\end{abstract}

Keywords: caftaric acid, polyphenols, Rosa damascena.

\section{Introduction}

Rosa damascena Mill. (Damask rose, Oilbearing rose, Pink rose) is one of the most important species, producing a high-value aromatic oil, which is used in the pharmaceutical, flavourings and fragrance industries [1]. According to the literature, "rose for sweetness" originates in Damask, the first capital of the Arab world. It is considered the national flower of Iran. The use of the essential oil of roses is known since the time of the Persian Empire and it is referred by physician and scientist Avicena, in the $10^{\text {th }}$ century BC [2].

Some scientific papers specify the use of emollient ointments and cold creams containing rosewater [3]. It is also known therapeutic use of the rose oil in respiratory diseases, asthma, hay fever, wound healing and skin infections. The Rosae damascenae flores rose contains vitamins A, B3, C, $\mathrm{D}$ and $\mathrm{E}$ [4]. In Romania, the flowers of this species are used for obtaining essential oil of rose syrup and rose sweetness.

Rosae damascenae flores total polyphenols was determined by a group of researchers from Turkey who showed hepatoprotective activity on a residue from the distillation of the fresh rose flowers [5].

The flowers of the family Rosaceae species are known in the literature for their content in polyphenols and vitamin C. Polyphenols are known for their antioxidant, anti-infective, antiinflammatory, anticancer, antimutagenic and antidepressant actions [6, 7].

Caftaric acid is the most abundant phenolic compound in many vegetal products [8 - 10]. The caftaric acid is used in cosmetic formulations for the treatment of dermatological disorders and for regulating skin pigmentation [11]

\section{Experimental}

\subsection{Plant material}

The flowers of Rosa damascena Mill. were harvested from Constanta on 1-3 June 2013.

The material was washed in quick water spurt and dried in warm air. It was performed identification of the species was kept in Pharmacognosy Laboratory, Faculty of Pharmacy, Ovidius University, Constanta.

\subsection{Sample preparation}

Tincture. A weighed amount (100 g) of the fresh rose flowers was extracted with $1000 \mathrm{~mL}$ of ethanol $70^{\circ}$ at room temperature, for 14 days. The tincture was filtered through a $0.45 \mathrm{~m}$ PTFE filter into a HPLC vial and capped.

Rose water. Rose water was obtained as follows: 70 grams of the fresh rose flowers was distilled with $1000 \mathrm{~mL}$ of water to a distillation apparatus for 3 
hours. The rose water was filtered through a $0.45 \mathrm{~m}$ PTFE filter into a HPLC vial and capped.

\subsection{HPLC analysis of phenolic compounds}

For separation, identification and quantification of the phenolic compounds was adapted a USP30 HPLC method [12]. The phenolic composition was analyzed qualitatively and quantitatively by HPLC system (Agilent 1200) with quaternary pump, DAD, auto sampler. Separation was carried out on Zorbax XDB or equivalent column C18, $250 \mathrm{~mm}, 4,6 \mathrm{~mm} ; 5$ $\mu \mathrm{m}$. A gradient elution was performed with solvent A (phosphoric acid) and solvent B (acetonitrile) as follows (Table 1). The flow rate was $1.5 \mathrm{~mL} / \mathrm{min}$ and the injection volume was $20 \mu \mathrm{L}$.

The retention times and $\mathrm{DAD}$ spectra were compared to available authentic standards.

Table 1. The gradient elution

\begin{tabular}{|c|c|c|}
\hline $\begin{array}{c}\text { Time } \\
\text { (minutes) }\end{array}$ & $\begin{array}{c}\text { Solution A, } \\
\text { mL \% }\end{array}$ & $\begin{array}{c}\text { Solution B, } \\
\text { mL \% }\end{array}$ \\
\hline $0-13$ & 90 & 10 \\
\hline 13 & 7 & 22 \\
\hline 13 & 78 & 22 \\
\hline 14 & 60 & 40 \\
\hline 17 & 60 & 40 \\
\hline 17.5 & 90 & 10 \\
\hline 22 & 90 & 10 \\
\hline
\end{tabular}

The concentration of the used standard solutions ( $70 \%$ methanol) were: $\mathrm{E}$ - resveratrol $=37 \mathrm{mg} / \mathrm{mL}$, $\mathrm{Z}$ - resveratrol $=0.22 \mathrm{mg} / \mathrm{mL}$. $\mathrm{Z}$ - resveratrol was obtained from $E$ - resveratrol exposed 12 hours at UV 254 nmradiation (fig. 1.). The following concentrations were obtained: caffeic acid $=0.36$ $\mathrm{mg} / \mathrm{mL}$, chlorogenic acid $=0.37 \mathrm{mg} / \mathrm{mL}$, cinnamic acid $=0.58 \mathrm{mg} / \mathrm{mL}$, vanillin $=0.42 \mathrm{mg} / \mathrm{mL}$, gallic acid $=0.39 \mathrm{mg} / \mathrm{mL}$, ferulic acid $=0.48 \mathrm{mg} / \mathrm{mL}, 3$ methylgallic acid $=0.34 \mathrm{mg} / \mathrm{mL}$, ellagic acid $=0.43$ $\mathrm{mg} / \mathrm{mL}$, p-coumaric acid $=0.51 \mathrm{mg} / \mathrm{mL}$, caftaric acid $=0.42 \mathrm{mg} / \mathrm{mL}$ (Table 2, Fig. 2).

The method was validated in terms of linearity, precision, accuracy, and specificity, limit of detection and limit of quantification [13].
Table 2. The retention time of standards

\begin{tabular}{|c|c|c|}
\hline $\begin{array}{c}\text { Nr. } \\
\text { Crt. }\end{array}$ & Compound & $\begin{array}{c}\text { Retention time } \pm \\
\text { SD }^{*}\end{array}$ \\
\hline 1 & $E-$ resveratrol & $14.467 \pm 0.017$ \\
\hline 2 & $Z-$ resveratrol & $15.751 \pm 0,058$ \\
\hline 3 & Caffeic acid & $4.598 \pm 0.036$ \\
\hline 4 & Chlorogenic acid & $3.501 \pm 0.015$ \\
\hline 5 & Cinnamic acid & $15.867 \pm 0.007$ \\
\hline 6 & Vanilin & $6.919 \pm 0.051$ \\
\hline 7 & Gallic acid & $0.990 \pm 0.025$ \\
\hline 8 & Ferulic acid & $8.565 \pm 0.058$ \\
\hline 9 & Ellagic acid & $15.303 \pm 0.027$ \\
\hline 10 & $p$-Coumaric acid & $7.187 \pm 0.019$ \\
\hline 11 & $3-o-$ Methylgallic acid & $2.606 \pm 0.008$ \\
\hline 12 & Caftaric acid & $3.013 \pm 0.021$ \\
\hline
\end{tabular}

("standard deviation for six injections)

\subsection{Setting detection wavelength}

In order to determine the wavelength of detection, a sample of caftaric acid solution, having a concentration of $80 \mathrm{ppm}$, was injected. After 10 minutes the absorption spectrum was recorded compared to the control (mobile phase).

Calibration curves of caftaric acid

The stock standard solution of each caftaric acid derivative was prepared as follows: about $4.2 \mathrm{mg}$ compound was accurately weighed and placed into a $10 \mathrm{~mL}$ volumetric flask. Seventy percent ethanol in water was added and the solution diluted to volume with the same solvent.

Calibration curves were established on six data points covering the concentration range of $2-50$ $\mu \mathrm{g} / \mathrm{mL}$.

Triplicate injections were made for each standard solution. Calibration curve was obtained by plotting the peak area.

\subsection{Method validation}

Linearity. The study of linearity was performed by the analysis of six standard solutions, in duplicate. Calculations were carried out by the leastsquares method (analysis of variance with statistical F-test, including evaluation of the model lack-of-fit). 


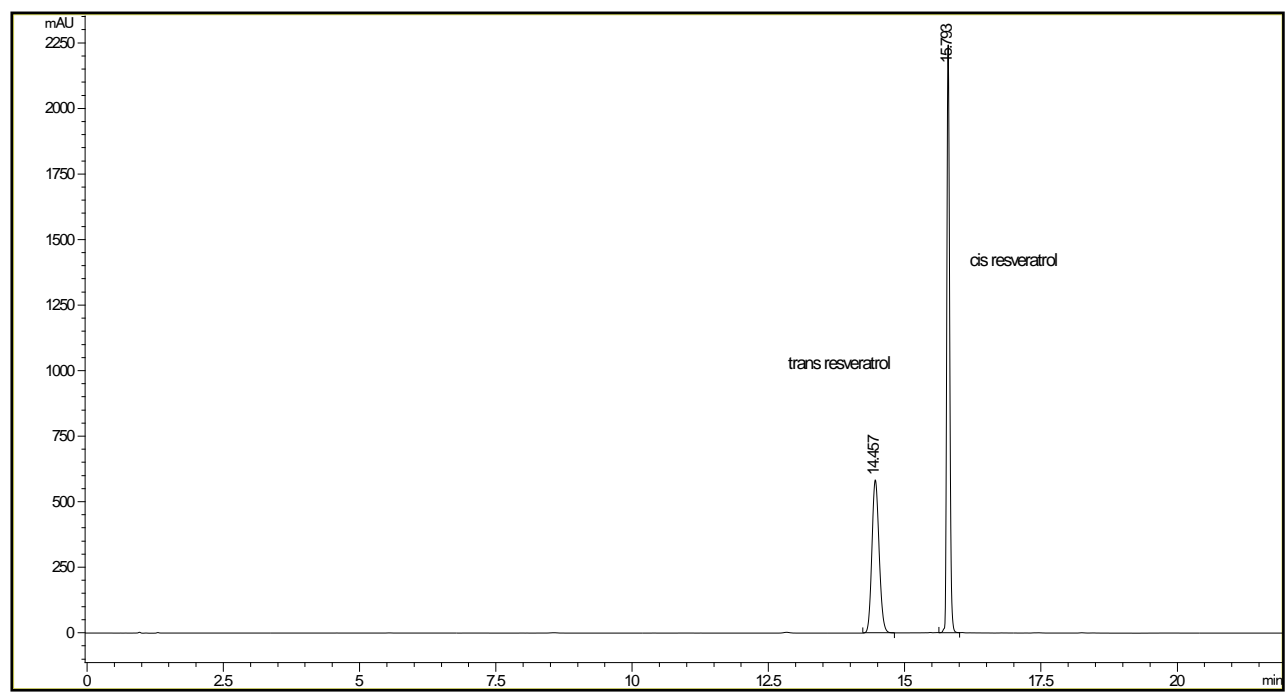

Figure 1. HPLC chromatogram of resveratrol after exposure UV $254 \mathrm{~nm}$ radiation

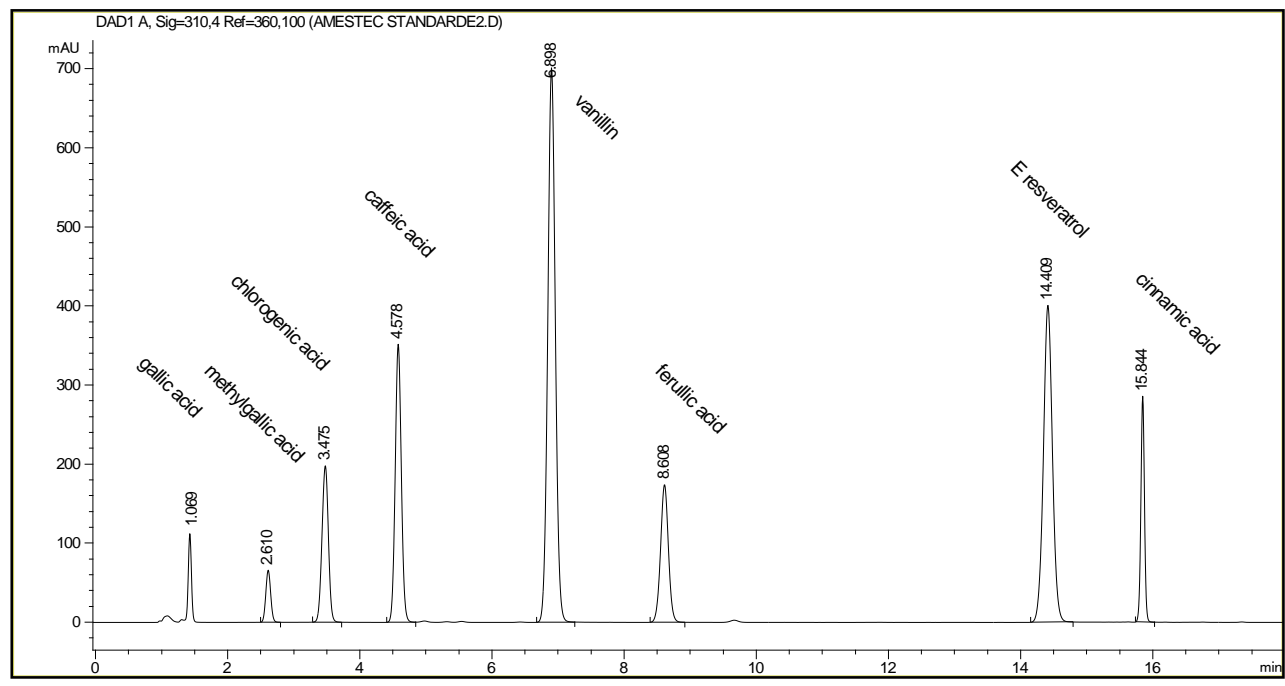

Fig.2. HPLC chromatogram of standards

Accuracy. The accuracy of the method was tested by determining recovery of caftaric acid added in tincture of Rosae damascenae flores, in known concentrations [14].

Precision of the applied method. Intermediate precision. This parameter was determined by repeating 10 times the same concentration of caftaric acid and tincture of Rosae damascenae flores injections for 3 consecutive days. Retention times and peak areas were statistically processed by determining the relative standard deviation (\%R.S.D.).

Repeatability. The repeatability was calculated from 10 replicate injections of caftaric acid and tincture of Rosae damascenae flores samples, under constant operating conditions (laboratory, equipment, operator, and method) over a short period of time.

Limits of detection and quantification. Limits of detection (LOD) were calculated according to the 
expression $3 \sigma / \mathrm{S}$, where $\sigma$ is the standard deviation of the response and $\mathrm{S}$ is the slope of the calibration curve. Limits of quantification (LOQ) were established by using the expression $10 \sigma / \mathrm{S}$.

\section{Results and Discussions}

\subsection{Setting detection wavelength}

From the analysis of the absorption spectrum of the caftaric acid (Fig. 3) shows that it has an absorption maximum at a wavelength of $330 \mathrm{~nm}$, which does not interfere with the absorption of mobile phase components.



Fig. 3. Caftaric acid absorption spectrum

In conclusion, best results were obtained at the wavelength of $330 \mathrm{~nm}$ in all stages of the determination, separation and dispensing of caftaric acid.

\subsection{Calibration curves of caftaric acid}

Calibration curves were established on six data points covering the concentration range of 2-50 $\mu \mathrm{g} / \mathrm{mL}$ (Fig. 4 and Fig. 5).

\subsection{Method validation}

Linearity. The relationship between the peak area and the caftaric acid concentration was evaluated over the range 2 şi $50 \mu \mathrm{g} / \mathrm{mL}$. Land was found linear $\left(\mathrm{y}=10.685 \mathrm{x}-5.3475 ; \mathrm{R}^{2}=0.9993 ; \mathrm{n}=6\right)$.

Good linearity (correlation factor $>0.9960$ ) was achieved in the concentration range $2-50 \mu \mathrm{g} / \mathrm{mL}$ for caftaric acid in ethanol 50\% solution (Fig. 6).

ANOVA (analysis of variance) is used to validate the regression model used. In order to obtain the assurance that there is currently no alignment fault, it was applied $F$ test (Fisher).
Fischer test is not significant, so there is a defect of alignment (Table 3 ).

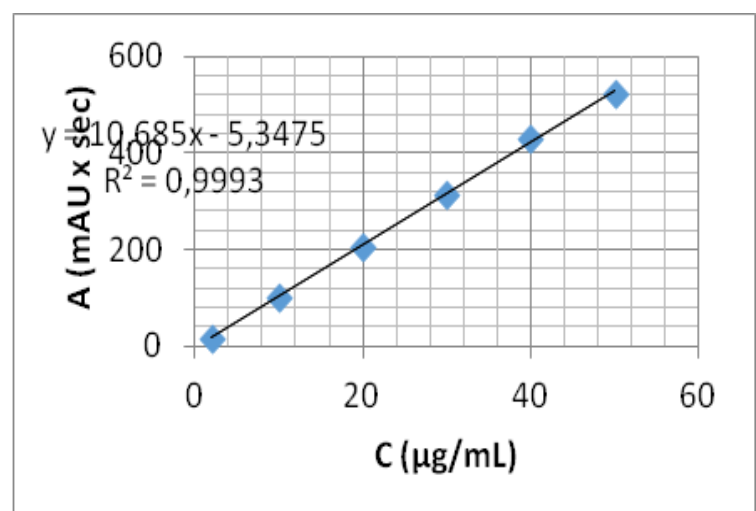

Fig. 4. Calibration curves of caftaric acid

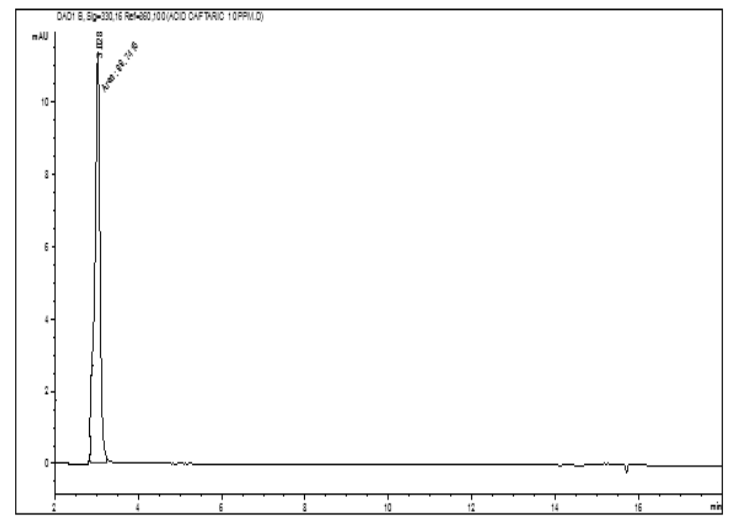

Fig. 5. HPLC chromatogram of caftaric acid

Accuracy. The accuracy of the method was verified by means of recovery assays. Adequate amounts of caftaric acid in Rosae damascenae tincturae in order to obtain added concentration 10 and $20 \mu \mathrm{g} / \mathrm{mL}$. The recovery values af the added caftaric acid ranged from $97.54 \%$ to $100.23 \%$ $(98.74 \% \pm 1.36 ; \mathrm{n}=3)$.

Precision of the applied method. Intermediate precision. The precision of the system was demonstrated by analyzing the 6 samples of the same concentration and of tincture of Rosae damascenae flores. Relative standard deviation obtained areas recorded $\operatorname{RSD}(\%)=0.5587$ and relative standard deviation obtained record retention times, RSD (\%) $=0.2906$ is less than $2 \%$. The RSD values obtained for the retention times ranged from $0.95 \%$ to $1.69 \%$ and the RSD values for peak areas ranged from 
$0.31 \%$ to $1.91 \%$ for real samples of tincture of Rosae confirm the accuracy of the system. damascenae flores. We can say that these data

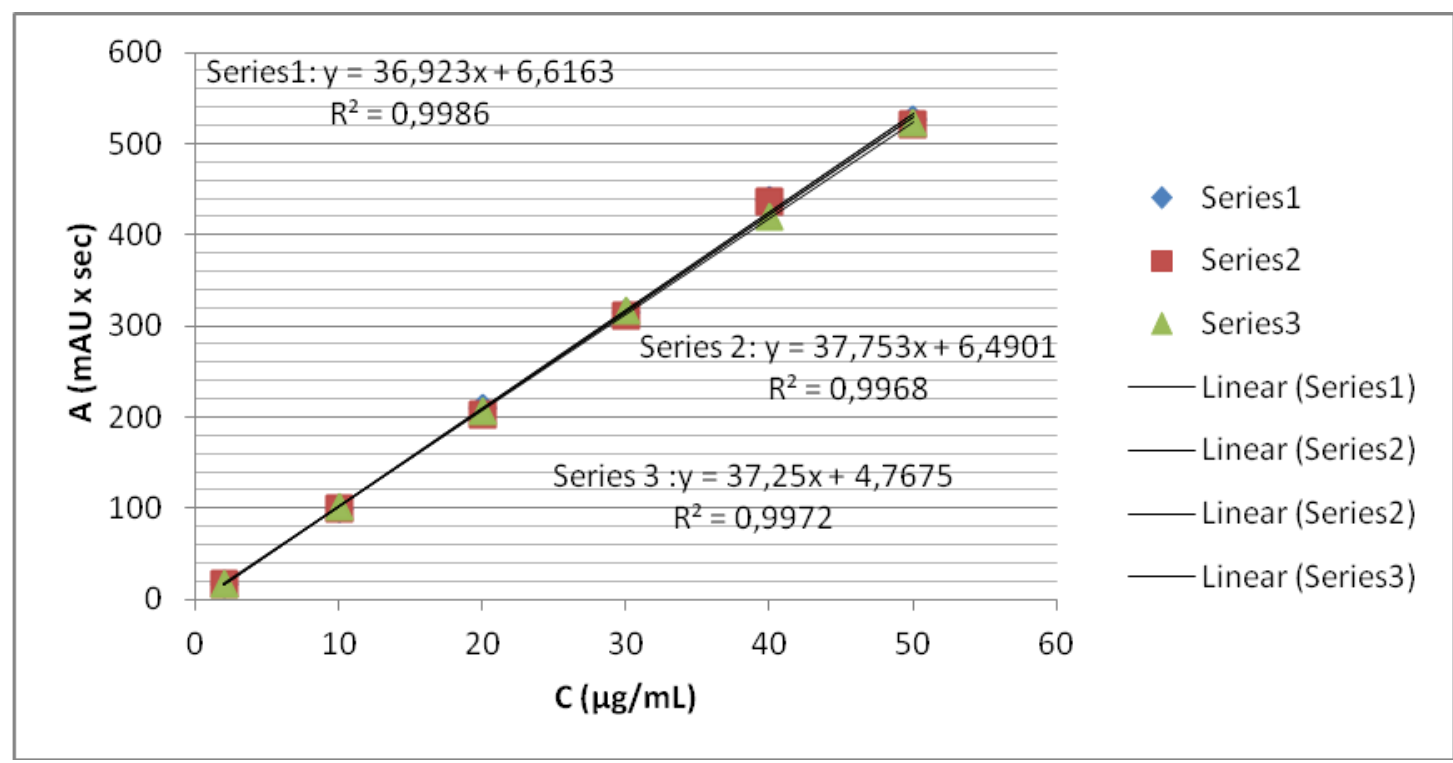

Fig. 6. The curves for each series of determinations

Table 3. Required parameters regression test Fischer

\begin{tabular}{|l|l|r|r|r|r|l|}
\hline \multicolumn{7}{|c|}{ ANOVA $^{\mathbf{b}}$} \\
\hline Model & Sum of Squares & \multicolumn{1}{c|}{ df } & Mean Square & F & Sig. \\
\hline & Regression & 190771.102 & 1 & 190771.102 & 4245.316 & $.000^{\mathrm{a}}$ \\
\cline { 2 - 7 } & Residual & 179.747 & 4 & 44.937 & & \\
\cline { 2 - 7 } & Total & 190950.849 & 5 & & & \\
\hline \\
a. Predictors: (Constant), VAR00001 & & & & \\
\hline
\end{tabular}

Repeatability. The obtained $\operatorname{RSD}(\%)$ value is 0.55 (below 2\%) for standard solution while the $\mathrm{RSD}(\%)$ value obtained for tincture of Rosae damascenae flores is $1.78 \%$. Those values indicate excellent repeatability of the proposed method.

Limits of detection and quantification. LOD = $1.8820 \mu \mathrm{g} / \mathrm{mL}$ and LOQ $=6.270 \mu \mathrm{g} / \mathrm{mL}$ were established by the procedures described in the Section 2.

\subsection{HPLC analysis of phenolic compounds.}

The following compounds were detected: cinamic acid, gallic acid, caftaric acid, ferulic acid, elagic acid and 3-o-methylgallic acid, for tincture (Table 4, Fig. 7) and for the rose water (Table 4, Fig. 8 and Fig. 9). 
Table 4. Phenols compounds and their concentrations $\mathrm{mg} / 100 \mathrm{~mL}$ sample

\begin{tabular}{|c|c|c|c|c|c|c|}
\hline Sample & $\begin{array}{c}\text { Gallic acid } \\
m g \%\end{array}$ & $\begin{array}{c}\text { 3-o-Methylgallic } \\
\text { acid } m g \%\end{array}$ & $\begin{array}{c}\text { Ferulic acid } \\
m g \%\end{array}$ & $\begin{array}{c}\text { Ellagic acid } \\
m g \%\end{array}$ & $\begin{array}{c}\text { Cinamic acid } \\
m g \%\end{array}$ & $\begin{array}{c}\text { Caftaric } \\
\text { acid } m g \%\end{array}$ \\
\hline Tincture & 876.037 & 33.328 & 2.897 & 1485.177 & 15.306 & 5.608 \\
\hline Rose Water & - & 0.0986 & - & - & 0.832 & 0.13341 \\
\hline
\end{tabular}

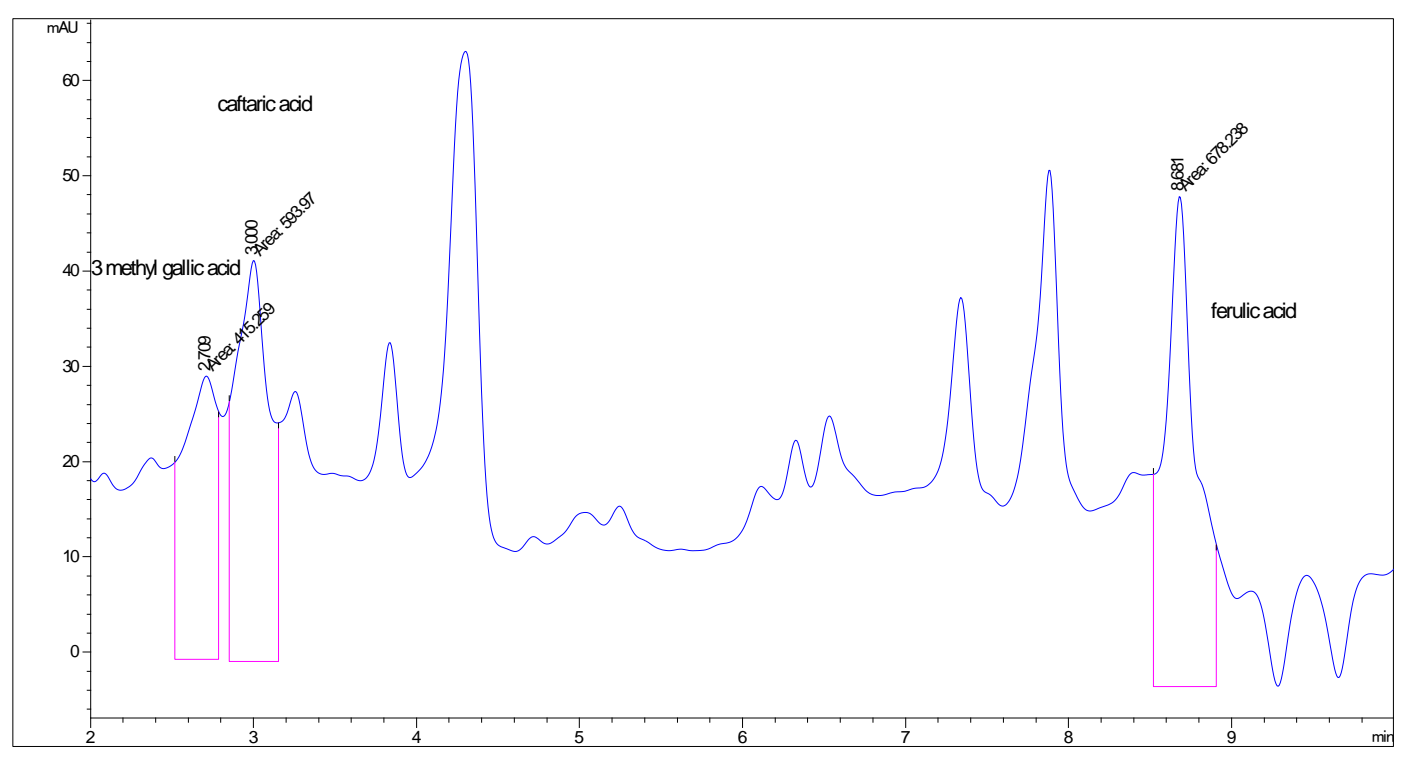

Fig. 7. HPLC profile of phenolic compounds from Rosa damascenae tincturae

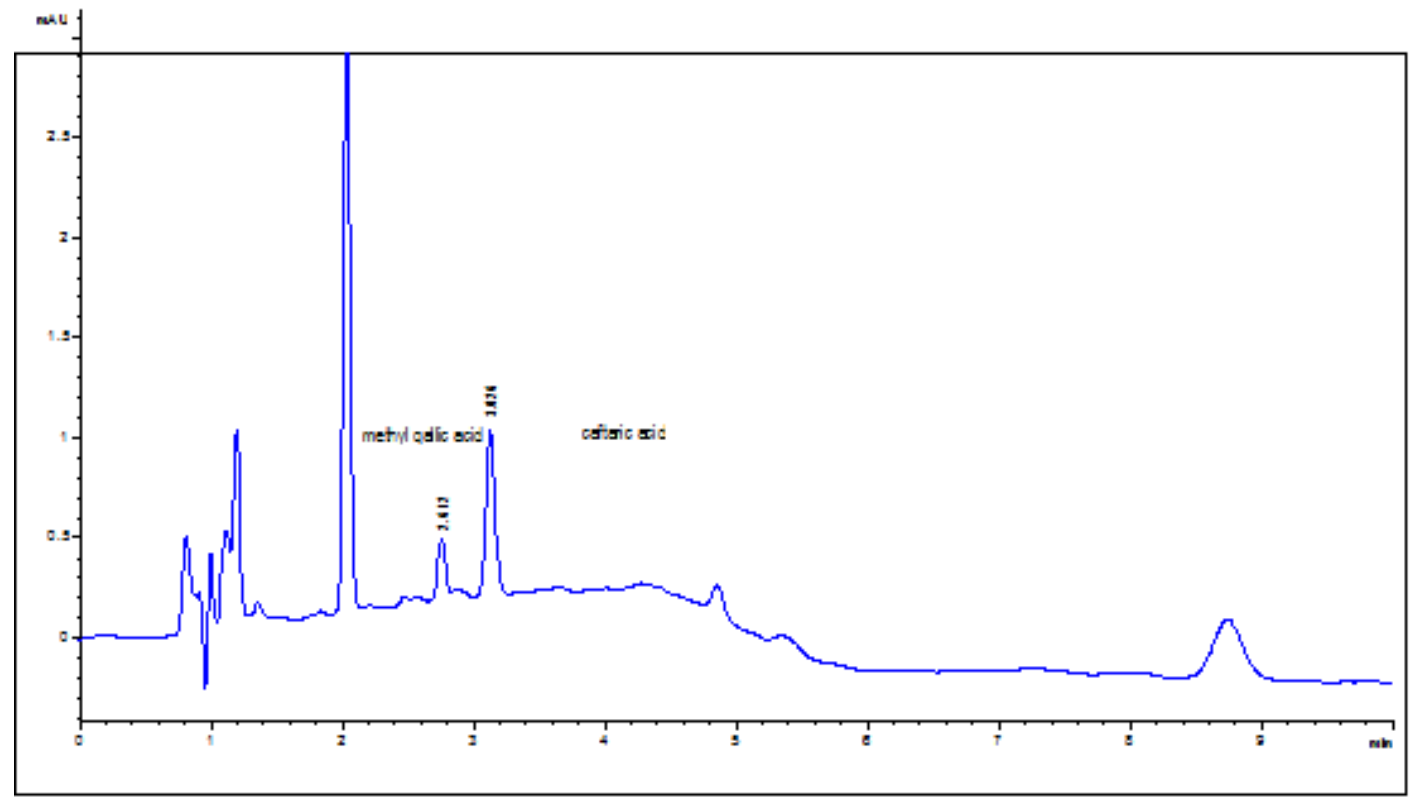

Fig. 8. HPLC profile of phenolic compounds from Rose Water 


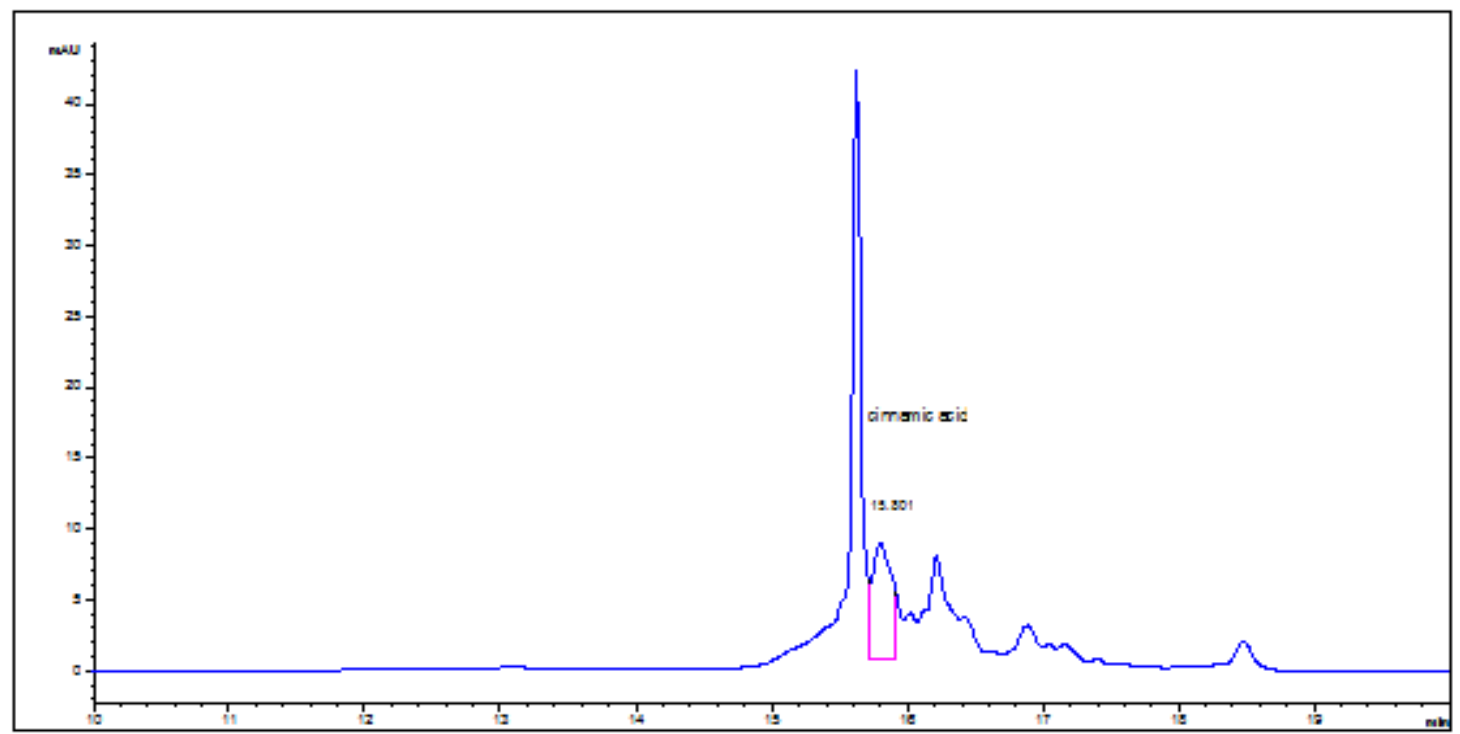

Fig. 9. HPLC profile of phenolic compounds from Rose Water

\section{Conclusions}

The proposed method was considered adequate, with regard to the linearity, precision, repeatability and accuracy of the results. Thus, it can be employed in the analysis of vegetal product.

In tincture were determined polyphenols known for their antioxidant action. Tincture of Rosae damascenae flores could afford health benefits by preventing unwanted free-radical-induced oxidative reactions.

The main active principle identified in tincture and in rose water is caftaric acid.

Since it is known the use of caftaric acid for regulating skin pigmentation, its presence in rose water can demonstrate the utility in cosmetic preparations.

\section{References}

* e-mail address: nmatei1977@yahoo.com

[1]. B.M. Lawrence, Perfumer \& Flavorist 16, 43 (1991).

[2]. A. Nikbakht and M. Kafi, VIII International People-Plant Symposium on Exploring Therapeutic Powers of Flowers, Greenery and Nature 790, 251 (2004).
[3]. H. Loghmani-Khouzani, O. Fini Sabzi and J.H. Safari, Scientia Iranica 14, 316 (2007).

[4]. M. H. Boskabady, M. N. Shafei, Z. Saberi and S. Amini, Iranian Journal of Basic Medical Sciences 14(4), 295 (2011).

[5]. C. R. Achuthan, B. H. Babu and J. Padikkala, Pharmaceutical Biology 41, 357 (2003).

[6]. O. Sagdiç, N.G. Baydar and H. Baydar, Food Science and Technology International 10, 277 (2004).

[7]. K.G.D. Babu, B. Singh, V.P. Joshi and V. Singh, Flavour and Fragrance Journal 17, 136 (2002).

[8]. A. Vanzo, R. Cecotti, U. Vrhovsek, A.M. Torres, F. Mattivi and Sabina Passamonti, Journal of Agricultural and Food Chemistry 55, 1604 (2007).

[9]. J. Darias-Martín, B. Martín-Luis, M. CarrilloLópez, R. Lamuela-Raventós, C. Díaz-Romero and R. Boulton, Journal of Agricultural and Food Chemistry 50, 2062 (2002).

[10]. V.L. Singleton, C.F. Timberlake and A.G. Lea, Journal of the Science of Food and Agriculture 29, 403 (1978).

[11]. M. Guitard, R. Bel Rhlid, A. Moodycliffe and F. Dionisi, Use of caftaric acid and derivatives in food supplement for regulating skin pigmentation, U. S. Patent No. 20130101556 (2013). 
[12]. *** NF 25, United States Pharmacopeia and the National Formulary (USP 30/NF 25). Rockville (MD), The United States Pharmacopeial Convention Inc. 2007, 914.

[13]. I. Stoicescu, A. Popescu, R. Sirbu and C. Bala, Analytical Letters 45, 2519 (2012).
[14]. F. Pellati, S. Benvenuti, L. Magro, M. Melegari and F. Soragni, Journal of Pharmaceutical and Biomedical Analysis 35, 289 (2004).

Received: 19 April 2015 Received in revised form: 25 May 2015 Accepted: 27 May 2015 